\title{
MOBILE PHONE SOCIAL HARMS (MOBILE PHONE, COMMUNICATIVE DEVICE OR CRIME TOOL)
}

\author{
H. Farnam
}

Department of Theology \& Islamic sciences, Payame Noor University (PNU), Iran

Published online: 16 July 2016

\begin{abstract}
One of the human inventions created in order to facilitate life but it became scourge for him is mobile phone. Ignorance on quality of using mobile phone and conscious use of it in inappropriate way will have consequences that it seems that it gradually becomes as social problem and harm. Author of this paper aims to warns against risks and harmful and abnormal consequences of it since he believes that mobile will be a factor for crime as several crimes are occurring currently through this communicative tool that some of them will be discussed in this paper. Then, author has provided some recommendations at the end of paper in two sections related to government (three branches) and people (users). This study is a review paper in which data were collected by using library method and author has used of relevant papers, books, and reports.
\end{abstract}

Key words: mobile; social harm; crime; factors causing crime, other inventions.

Author Correspondence, e-mail: Ha.farnam@yazdpnu.ac.ir

doi: http://dx.doi.org/10.4314/jfas.v8i2s.22

\section{INTRODUCTION}

Several tools were invented during human life. These inventions are made to facilitate human life and comfort him. Thus, size, weight, and cost of them gradually reduced and capabilities of the inventions increased. One of these inventions is a mobile that has been developed significantly since the advent of its primary and non-advanced types in the 1880 s and it has 
become an important means of communication in human life, so that few people can be found in the world have not used it. Mobile phones also passed the evolutionary path governing on

They converted from large, heavy, and low-application tools to small samples, beautiful, and highly efficient tools used widely and even they became a ceremonial tool. Nowadays, every person in the world allocates part of his income this means of communication and considers it part of his life essentials. Several functions of mobile phones such as radio, TV, Digital camera, SMS, Bluetooth, sending images have attracted many users, so that a number of mobile phone owners enjoy ancillary functions of them than the main function of them, and they are seeking to provide more advanced types and versions of them for wider use of them. However, Unfortunately, ignorance on the quality of use of these tools, and sometimes consciously, but inappropriate use of them, as other human creations, lead to unwanted consequences affecting users and they understood the risk when the opportunity has lost or it is so little to prevent unpleasant consequences. This is opportunity at least as reminder and warning against dangers of this means of communication. Although, religious and traditional Iranian society and its belonging to deep Islamic culture have ensured Iranian society against such risks, we should also be aware of the threats that Islamic community facing with them. The present study is a case study conducted to investigate one of the harmful and crimecausing factors. Criminology and social science scholars and researchers seek to identify the factors affecting crime committed by people. Additionally, researcher in this paper aims to explain new hypothesis that still a few people have paid attention to it and it has not probably converted into a dilemma, while researcher believes alarm sounds in this regard and the treatment should be done before the event. Introducing of new tools in human life undoubtedly had a great influence on his comfort, but they create serious problems sometimes for civilized human due to his deviation from the proper use of these tools. For example, the multiple and diverse mobile applications can be noted. Nowadays, the numerous benefits of modern technology are obvious. Convenience and ease of using, wide applications of this new technology, its low cost, and its wide availability in Iran, have led that it become as a national and inclusive tool, so that even unemployed women and students also have it. Wide and comprehensive use of mobile phones and abuses of this tool may be separate topics in the field of research. For example, Japanese analysts examined the effects of mobile phones on students and they believe they have various positive and negative impacts on education of people [1]. The main concern of this paper is to examine the challenges and harms caused by improper use of the mobile phone. Although, it is not considered a major factor in the 
incidence of crime, we should not overlook its role as communicative tool in paving the ways to crime. As it is a tool available for human, it is charged or questioned less, while it plays an important role in paving the way for crime. For example, people addicted to their mobile phone are constantly thinking about it, when mobile phone is not with them[2]. The aim of this paper is to challenge the use of mobile phones in Iran and and pervasiveness of this means of communication. Nowadays, police and security forces protect from country's borders against drugs, alcohol, the satellite television, Ecstasy, outdated drugs, and other items compromising political, economic, and cultural order and security of Islamic society. They even bestow martyrs and injured people for this land, but no one shown any sensitivity on the arrival of all kinds of mobile phones along with various applications shipments containing this tool are sometimes confiscated under title of contraband at the excuse of that it has not been remained hidden from the security forces' eye! On other hand, by providing needed expenses, government has made it possible that different classes of people use this tool at all level of income and a few of people even in villages can be found that does to use this new tool. However, the culture of using it has not been trained and educated and most of its owners prefer its unconventional and uncommon use on its common and main use and cause problems for themselves and others.

\section{METHODS}

This study is a review paper in which data were collected by using library method and author has used of relevant papers, books, and reports.

Theoretical bases

Nowadays, the mobile phone has especial place in individual and social life, as one of the manifestations of modern communication technology and it is an integral part of everyday relations. It can be claimed for many people cannot live without it, or at least they have no utility. The popularity of mobile phones have reached a point that it hides its serious and essential harms that can be studied in social, cultural, behavioral, psychological, medical, legal, penal areas, and its adverse effects can be realized by a little curiosity in this regard. In fact, it can be a great source of problems from a pathological point of view so that it has penetrated in life of its users clearly. Recent studies in the field of medical and behavioral disadvantages on mobile phones around the world reveal that it is necessary to review the use of this widely used tool. All users, service providers, legislatives and governments need to realize the nature of different types of harms and their influence domain[3]. Mass media such as mobile phone have led to better communication with people outside of family and aliens, 
while it has weakened the relationships among members of family. Establishing relationship between family members is not very deep due to the workload in modern societies, while establishing an emotional relationship with others is the characteristics of the human spirit. Thus, people satisfy this feature and need to establish communication by using devices such as mobile phones [4]. According to the findings of social pathologists, reduced verbal communication and weakened family ties is gift of mobile phone to families. Technology entering to every society requires providing knowledge and culture on its use. Unfortunately, scientific achievements such as the Internet and mobile phone in Iran have been provided without training the culture of its using. In addition, based on researchers conducted by social pathologists, mobile waves have negative consequences for people, causing aggression and brain damages among the people [4]. These effects are not limited to social and pathological effects, but electromagnetic waves of mobile phone systems have negative effect on body of people. Some of the effects of these waves are headache, dizziness, insomnia and negative effect on cell division. Some group of researchers has conducted studies on them and claimed that mobile phone electromagnetic waves exacerbate these problems. Therefore, some of the negative effects of these waves are recognized and proven physically[5]. Therefore, mobile phone is a useful tool for communication, but if used improperly, it can be dangerous as firearms in public. High memory to store compressed audio and video files, audio recording, video recording, and various capabilities are other features of these means of communication. Majority of people can be seen working with mobile phone. They are talking or using its peripheral technologies such as games, Bluetooth, SMS, music and so on. Along with the development of multi-media new generation of mobile phones having video cameras and Bluetooth system, the negative consequences of this new technology are continually evolving and complex. Violations in cyberspace and the distortion of moral and legal values due to mentioned violations and abuse of the mobile phone, reducing face-to-face contacts, are some problems of this technology [6]. Thus, the mobile phone is considered as main factor of delivering messages in crimes such as violation of the dignity of people, spreading lies and disturbing nowadays [7]. With regard to Bluetooth, it must be said, that unfortunately in Eastern countries including Iran, having ancient civilizations and cultural and moral values higher than many Western countries the use of Bluetooth is different, so that its use optimistically is limited only to send audio and video entertainment content, while in more realistic view, it is limited to send and receive anti-cultural and non-moral content through mobile phones. Accordingly, entering to privacy and personal life of people has widely created troublesome for the community [8]. Pathological effects of it on those who use this 
device are so significant. The results of some studies found that most mobile users are those people with low self-esteem and have difficulty in social relationships and feel they be in constant communication with others. Based on this research, there is same physiologic basis between drug addiction and behavioral addictions. Even researchers believe that turning off the mobile phone cause anxiety, allergies, sleep disorders and insomnia, shivering and digestive problems for mobile users. In this regard, various aspects of addiction to texting include: to spend a lot of time for texting, preoccupation, mental preoccupations about texting and conflict with other in texting. In addition, to regret about the time spent for texting, using the short message for the thrill-seeking and social relationships with others, leaving assignments and lessons to satisfy the addiction to mobile are some of the disadvantages of it in this regard [9]. The serious problem is excessive use of mobile by students. Although some believe that the use of mobile technology has no negative impact on the education of students and help them in learning materials, we should say that negative effects for students are more. Lack of control and organize students to use this tool highlights the adverse effects of it. Immoral to use private photos to share it is still prevalent in the classrooms. Excessive use of mobile phone in the classroom detracts the focus of students leading to their academic failure. Sending, receiving, and reading short text messages are highly prevalent among young people and this new communication media has been replaced by books [10]. Another approach that author has considered it in a separate research project is relatively new approach that is perhaps less number of people consider it due to religious and traditional space governing of Iranian society. Unfortunately, this approach is emerging very slowly. While Iranian couples often use mobile phone for quick and easy access to their mates, it seems that lack of information on position of mobile subscriber during responding it and the possibility of secrecy and private nature of this issue so that others cannot control it, and sending and receiving message in a way that identity of sender and receiver is unknown caused complicated problems for some families. Although it is not serious still, it has been source of domestic disputes and conflicts. Fortunately, it is not considered as one of the causes of social disorder, but it is not reasonable to neglect in its pathology. When a man is observing a list of stored numbers on the phone of his wife that some of them belong to a strange man or when a woman discovers her husband has receives a text message that he is trying to hide it, or when each of them has stored a number of photo and image and SMS in his or her mobile or display them on wallpaper of mobile while his or her mate is not willing to do it, a solutions must be sought [11]. Perhaps, it is unusual and funny to hear that a Saudi woman seeks divorce because her husband selected a photo of strange woman on his mobile 
wallpaper, but we see such behaviors and problems in our society. Studies show that mobile phone is one of the main factors in divorce of Arab couples in some Arab countries in recent years. For example, Iraqi court stated that many of the divorces are due to mobile phone in which mobile phone of each of them is called and leads to lack of satisfaction of other one or sometimes some contact numbers are found in phone list of one of them causing suspicion in this regard. Mass media such as mobile phone has increased the mean rate of divorce in Saudi Arabia. It seems that as most of marriages are monogamy in Iran, they have high durability. Mobile phone is not major factor, but it is considered as one of the factors causing disputes among Iranian spouses. Sometimes, SMS or anonymous numbers lead to dispute among couples [12]. According to sociologists, severe conflicts are effects of false Bluetooth on families, causing tension and suspicions among members of family. Lack of emotion and unkindness towards couples and weakened religious foundations of people are other effects of false Bluetooth [13]. SMS is also problematic in this regard, as another facility of mobiles. Sending offensive short message by purchasing Iran cell SIM cards that are cheap children has increased [14]. However, it is obvious that these destructive and negative effects are not unique to mobile phones and other media such as television, satellite and the Internet play role in this regard. A study in Iran showed that the most important area of influence of satellite TV programs for children and adolescents at the individual level is corrupt and threaten physical, psychological and behavioral health. The impact for youth is corrupt, mental, and moral modeling, and it is fun and filling leisure time of adults. The most important negative effect of satellite TV programs at the social level is creating cultural conflicts in society and promoting the culture of consumerism in society [15]. Officials and authorities are aware of the negative consequences of media such as mobile phones and acknowledge that mobile phones have created cultural challenges in our society we have created. Considering value foundations, mobile phone can have both constructive and destructive aspects. The positive or negative effect of this effect depends on the rate of overcoming and entering of interaction through mobile and other devices. Despite the fact that our society is based on moral values and Islamic culture, unfortunately, tool expansion of mobile has been considered in recent years. Although, it is necessary, it has promoted western culture rather expanding Islamic and Iranian culture unconsciously. It is result of lack of inclusive thinking in expanding the technology, and it is true in other areas [16].

Given the subject of study, it is necessary some factors which have impact on crime to be discussed briefly here: 
Criminologists have divided factors affecting the crime to two major categories of internal or individual and social factors.

Internal causes or factors are a combination of factors associated with human features and characteristics that are originated from his physical and/or psychological existence [17]. Internal factors are divided into two groups of hereditary and acquired factors. Hereditary factors are those factors that children have received them from their parents since their birth, while acquired features of human cause that some part of his inherent or hereditary potentials or be realized or suppressed. These features sometimes affect embryonic development involuntary such as injuries during pregnancy and childbirth, and sometimes they are acquired voluntarily, such as willingness of individuals to use drugs [18].

External factors

In addition to studies in biology and psychology that are mainly on physical and mental factors criminals, many researchers have emphasized on social and environmental aspects influencing the behaviors and conducted studies in this regard. Criminal sociology, as a branch of criminology, studies the importance and crucial role of external factors in the phenomenon crime. External factors include factors that constantly influence human in environment, triggering his behaviors. These factors are many and varied related to various aspects of human such as social environment including family and education and business location and natural, cultural and economic environment. Based on their own education, experiences, and expertise, ach of researchers have studies one or some of these factors and provided their results. The subject of this paper is also included within these factors, external or social factors. Social environment around people sometimes puts them in conflict with other people. This environment sometimes is accidental. Environments such as garrison, school and university or places where people are trained professionally are considered as accidental environments. Sometimes a person is involved in the selection of environment. The family that one selects to begin his marital life, places one selects to spend his free time, type of entertainment that one selects, and even favorite mass media that he selects are included in this group. However, sometimes people are also placed in an environment where people have no role in its selection. In fact, environment is social imposing itself on them. Detention, prison, correctional centers are places where people have never willing to stay in them. Therefore, these places are called forced or compulsory social environments [19]. Since the hypothesis discussed here is that the mobile phone causes crime, some of the crimes caused by mobile are discussed in this section.

Dissemination of immoral and pornographic images and videos 
Based on the evidence, SMS and Bluetooth are among the facilities available in the mobile phone considered increasingly by people, especially young people. Based on available statistics, over $70 \%$ of the contents exchanged by SMS or Bluetooth include parody, vulgar jokes and immoral texts and images. Based on pathologists, new generation is always seeking to respond its needs and when they are not met, technology too is considered the best option to meet the needs that social security may

be compromised due to lack of appropriate teaching the culture and legal gap in this regard [20].

\section{Harassing phone calls}

Currently, each of the users are not forced to wait in long lines and pay high prices to purchase a SIM cart, as years when mobile phone entered to country, since thanks to the activities of private operators, each user can own SIM cart with minimal cost as it registers. While this situation may be partly contributed in cost and time for users, for it has provided serious problems for them. One of the main problems is harassing phone calls difficult to persecute and identify. Based on the statistics, most of these intruders use credit SIM cards and they are under 18 years old.

Experts believe the supply of cheap SIM cards unsystematically and in non-compliance with regulations of demand and subscription for subscribers has increased dissatisfaction with harassment phone calls, and this situation has caused a serious social problem in the social problem in the country's mobile network. It is considered a crime under Article 641 of the The Islamic Penal Code[21].

\section{Harassment of right}

Due to availability of mobile and decreasing age of subscribers, this means of communication opened its place among the educational institutions such as schools and universities, and it became a serious problem in learning environments, especially schools. Nowadays, talking slowly by mobile phones, playing games, texting, and Bluetooth have been replaced by many whispers and chatter of students, and they sometimes force teachers to ask them to turn off their mobile phone or set it in silent mode, but there is no hearing ear for those who prefer mobile phone over pamphlets and books [22]. Such harassments for teachers and professors and other students are considered as crime under Article 690 of the The Islamic Penal Code.

Other people phone data theft and extortion

According to security experts, hackers are equipped with available commercial software and accordingly they can easily recover deleted data from mobile phones such as address book, calendar, contact numbers, photos, videos and e-mails, and make the mobile phones as 
discovered treasure for personal information thieves and let them buy the information off the internet [23]. More recently, unfortunately, inserting malware in memory card of mobiles done by some mobile repairmen without the user's permission has caused problems, so that a call is contacted or a SMS is sent to phone of somebody that user do not know him and has no his contact number. Then, owner of unknown number misuse the mobile phone of owner of repaired phone[24].

Additionally, some mobile users, along with using MMS, make films of some people and use them to extort money. In the case of refusing the demands of that person, the possibility of sending the image for all people is possible in the shortest time [25].

Fraud

According to statistics reported by police, mobile phone fraud is increasing, especially in the sale of SIM cards. In this regard, criminals attempt to mislead users and sell an unrealistic commodity services with some sentences. Some example of a telephone conversation is as follows:

Hi, we contact with you of Hamrahe Avval mobile office, your phone number won in Anthology project, so you have selected. Similar to your phone number but the credit type with number $0910 * * * 1769$ is available costs 40 dollars, but as you have won in the anthology project of Hamrahe Avval, this SIM card will be provided for you at cost of 300000 ! In this contact that SIM card is especial with initial charge of 80000 Rials and and 90 minutes of free calls within the network. Then, fraudsters claim that this SIM card will be sent you until tomorrow afternoon that after getting your full name. In these types of contacts, no opportunity is given to user to think. Advertising to sale SIM card similar to your number with different area code but at lower cost is another method of fraud to sale SIM card in market. However, the given promises are not similar to incentive plans of Hamrahe Avval, for example, initial charge in Hamrahe Avval Plan is 50000 Rials, while an incentive plan of 80000 Rials is promised. In three incentive packages in the winter plan of Hamrahe Avval, three-month free use of GPRS and MMS cannot be found, and only three-month waiting sound is free, while the seller promised free use of the internet and MMS service for the three months [26]. Sometimes it is observed that text messages are sent to mobile phone of users that contain a particular message for them. In these messages, it is said that if you SMS with the specified text, amount of charge will be added to your SIM as gift or you will be participated in quiz and a raffle with valuable prizes. In such cases, by sending SMS in response, specified sum is deducted of credit of victim's SIM card and it is added to sender's 
SIM card. While this sum is not so much, fraudsters will gain much money due to large number of victims [27].

\section{Hacking SIM card}

The term hacking of mobile phone means that it can be permeable by hacker. Accordingly, hacker can get information of that person phone easily. In fact, the stranger can see the content of victims' mobile phone in his mobile phone. However, it was done through computers and Internet cyberspace firstly. Hacking the phone number of other people can be done in several ways, but the most common method is through Bluetooth in which offender identifies the mobile phone of people whose Bluetooth is turn on and he sends a particular file for victim. When victim accepts his request, his mobile phone is hacked and information of his mobile phone will be provided for offender [28]. It has also said that sometimes by sending a particular message to various SIM cards, sender will be enables to find a way to discover some of the digital codes. According to the security experts, defects in mobile phones have placed millions of people at risk of espionage and theft of data. If this technique is used, criminals can potentially listen to phone calls or steal money[29]. Mobile penetration and access to their data, either for extortion or curiosity purposes, subject to persecution and punishment under the computer crime law passed in 2009.

Invasion to privacy of people

New facilities provided by some operators such as Rightel open the way for new criminal activities for criminals and opportunists. It is enough that mobile phone rings and a child pick up the phone and provide all information of home to other party. Even the film of male and female people at the same style living in house can be easily observed and stored. In terms of security, the burglars can get the information of homes through this environment. In addition, some irresponsible and opportunistic people recording video at public events limited to women, including carnivals, stadiums and pools, leading to invasion to privacy of some women, and sexual and even life attempts [30].

\section{Spying}

While smart technologies of mobile phones are increasing in our country, security issues of these mobiles phones becomes more accurate and detailed. The important thing is that America and European countries that have tried to impose sanctions against Iran in various fields, the question is that why smart phones or similar technologies have not been sanctioned so far and they have not done any action in this regard. In this regard, many companies and valid sites have announced warnings on spying of smart mobile phones, while many users of 
such mobiles ignore it. More importantly, politicians, especially members of Parliament, should be more sensitive to this issue. However, this sensitivity is not seen in many of politicians of our country unfortunately [31]. There is also an application called Call-up that designed for smart phones that allows the information of people to be disclosed. This software makes your data be disclosed while you are not aware of it. Your information is provided for someone else just by a phone call. By this software, listener already knows that he is lying or not, since your personal information is in front of his eyes and your tone and voice of your speech is also investigated. While the aim of this software in UK is to combat against counterfeiting and fraud, but lack of restrictions on its use makes this phone to be a spying service tool for the Zionists[32]. In stating spying power of some new mobile phones, it is enough to know that Obama, President of America has no right to use Apple products known as iPhone due to security reasons! [33].

Facilitating drug trafficking and crimes against chastity

According to statistics of police, unfortunately, despite the fact that Bluetooth is a way to limited communication in society, people such as traffickers and street women use this method in places like complexes, malls and hotels to communicate with people that ultimately may cause problems for the audiences. In the Bluetooth area, sent materials begin with educational videos and events, humor clops, and ultimately they lead to immoral subjects[34]. Blasphemy

Most recently, sending messages and images containing blasphemy is common in the areas of SMS and Bluetooth. Seeing any destructive video, message, and image affect people based on their age. This issue is not unique to Iran and Islam, but in many countries, media contents have been separated into under and higher 18 years old [35].

Illegitimate relationship

Illegitimate relationship under Article 637 of the Islamic Penal Code considers sexual offenses lower than adultery, and based on principle of interpretation in favor of the accused, actions committed in this area must subject to this Article. However, it has been observed in most cases of conversations or exchanging of text messages between boys and girls or men and women which no marriage bond is between them, illegitimate relationship has been proven by private prosecution. Inclusiveness of mobile phone, its availability for all groups of people at all ages have paved the way to crimes at wide level of society that its criminals are not merely young people, but sometimes adults are involved in this regard.

Manslaughter and unintentional bodily injury 
There are numerous cases of fatal accidents or injuries that main cause of them was phone conversation, sending short message, and finally distraction led to accident and injury to him or others. Traffic laws have not been effective in this regard. In addition, programs such as Tango and WeChat have increased the decentralization of driver. In addition, mobile phone and especially new software has been introduced for this tool, including Viber, WeChat, Line, Instagram, tango, Chat-on has increased crimes such as insulting, swearing, threats of crime and even spreading lies and disturbing public opinion by criminals. While these crimes may be committed by other communication means, as mobile phones are available for all, and they are cheap and relatively they are hard to identify, criminals committed by them are higher.

\section{CONCLUSION}

Despite numerous benefits of various facilities of mobile phone, it has created some problems for people, that the most important problem is that it has become a tool to commit crime. Crimes such as hacking SIM card, spying, fraud, information theft and extortion, illegitimate relationship, invasion to privacy of people, harassing phone calls, immoral and pornographic images, murder and unintentional bodily injury, defamation, obscenity, threat of crime, spreading lies, disturbing public opinion, and facilitating crimes such as drug trafficking and crimes against chastity are some of these problems. Nowadays, abuse of mobile phone has made that it become dangerous as firearm or even a nuclear weapon. While use of firearms or nuclear weapons is limited or not possible in our country, it is not true in mobile phone. It is therefore worthy that people and authorities consult and collaborate to find a solution in this regard. Some recommendations addressing two groups of people (mobile phone users) and government (three branches) are provided here.

Recommendations

Recommendations to users

- Adherence to religious beliefs about the sanctity of invasion to privacy of people and the sanctity of disclosure of of private life secrets of people provided for them intentionally or unintentionally through this device.

-Commitment and dedication to enjoining good and forbidding wrong, at least among relatives, especially members of family, in which criminal use of it is forbidden.

-Paying attention in purchasing mobile compatible with the actual needs society in which we live. Having some mobile phones not only is necessary for some people and they can do their ordinary works without them, but also they are not cost-effective, since cost of installing 
software or repairing some mobiles are higher than cost of one ordinary mobile phone. In addition, the likelihood of crimes will be high by more advanced mobile phones.

-Caution in cases in which it is necessary that mobile to be given for someone else for any reason, including installing software or even the temporary use. Specific groups such as women and politicians must show greater sensitivity in this regard.

- Caution and avoid unnecessary installing of software or unnecessary download of applications that have often a formality aspect, causing just problem for Iranian users due to culture and life style of Iranian people

-Paying attention to security and police warnings on use of products of some mobile phone manufacturers that most of which are foreign companies.

-Resistance against children attempting to convince parents to provide mobile phone and it accessory facilities, while they are unaware of its use and possible risks. This recommendation is highlighted in the case of under 18 years old children.

Proper and reasonable training of children needing to use mobile phone. Aggressive guidelines and notifications usually give inverse result.

- Intangible but subtle and useful controlling and monitoring of children using mobile phone, especially children who are under 18 years of age

-Being an appropriate ideal or model for children and other family members in the field. Unfortunately, some parents are guilty of some crime by mobile phone, so we cannot expect that their children show appropriate behaviors in this regard.

-Parents' monitoring on money paid for their children (pocket money) both in terms of quantity and in terms of quality of cost spent on children. Unfortunately, some families pay money daily, weekly or monthly for their children, while it is not needed and they have no control on this issue that how their children spend it. Monitoring and controlling children in this unique field is not limited to control of spending of children in the mobile, but also it is vital in the prevention of drug addiction and alcohol abuse, and so on.

Recommendations to government (three branches)

Recommendations to Legislative branch

-The legislator is expected that establish some prohibitions considering age of mobile phone users due to challenges in this regard, as he shows sensitivity in freedom of individuals to use certain devices such as firearms, or driving motor vehicles requires that people have at least 18 years of age and other cases of this kind, because the risks of improper use of this tool is not less than dangers of driving by under 18 years old person without a license or presence of weapons in the eyes of ordinary people, with this difference that motor vehicle is easily 
visible in the streets and roads, while the mobile phone is in the pocket of everyone and it is not easily visible.

- Regulatory laws on foreign imports, especially highly advanced mobile phones and spying devices in some cases and banning such phones.

-Obligating the operator to provide SIM cards with the name or birth identification information so that any SIM so that can be identified and prosecuted in case of abuse.

-Legislations to ban the sale of mobile phone charge to certain segments of society such as children. As it is illegal to sell tobacco to children, it is good to show sensitivity in selling phone charge to them and it is better that charges to be purchased by parents. Parental supervision and monitoring will also complementary in this regard.

\section{Recommendation for judiciary}

Judging fairly but firmly and seriously on mobile phone users who invade invasion privacy of people and those who abuse it to spy and theft and extortion.

\section{Recommendations for executive}

-Arranging and holding training workshops with the subject of introduction to mobile intelligence society and crime in its area, firstly at the level of the special people of society, then sections. Experience has shown that much of the mobile phone crimes are associated with ignorance mobile phone user and if he was trained in this regard, he did not commit crime. This training and education at the children and young people level can be presented in the form of an attractive and useful booklet, and they can be trained by experienced and wellinformed people in schools.

-To ban carrying and using of mobile phones in all educational environments, especially in schools. It seems that the harmful effects of mobile phone use in public spaces, especially educational environment, is not less than harmful effects of smoking in public places.

- Professors and teachers should be model for their students at all academic levels. Unfortunately, professors and teachers sometimes use mobile phone while teaching, when time of class belongs to students. In addition to loss in time of class, they become improper model for their students, so we cannot expect students so much.

-Authorities must revise cost of using mobile conversations and other costs in using accessory facilities of mobile phone and mobile operators and companies should not think on their 
pocket and create market where every child can purchase mobile phone charge by his daily pocket money.

-Security forces and police must be more informed and updated than users in the field of mobile new technologies, and they should be fully armed with information and technology so that they are surprised by offenders in this regard. Nowadays, street combats with the police have changed to combat in cyber space, and lack of knowledge in this regard is like that we combat with drug traffickers without gun and ammunition.

-As, fortunately, police and security forces are not considered forcibly oriented arm of government authority are not considered authoritarian part of government and they are involved in cultural and social fields, especially in prevention, activating educational and informing mechanisms in society leads to popularity of police forces and it creates culture in the regard.

IRIB has made movie and TV series to warn against social problems and factors causing offense and crime. Unfortunately, in the field of mobile phone and its social and political problems, no work has been done, while abuse of mobile phones is trained in these films and TV series. It is better than authorities to take a step in this regard.

- Preachers and Clergymen can play an important role in raising awareness of the public and less educated or uneducated families can be justified regarding bad effects and harms of these means of communication. Experience has shown that the influence of the clergy supreme speech sometimes is more effective than effects of several films and books and research papers. It is worthy that Islamic Development Organization and other relevant organs and even Friday Prayers Imams to speak and warn against on adverse consequences of improper use of mobile phones, especially among children and youth by doing sufficient investigations and having full preparation to answer probable questions of audiences.

\section{ACKNOWLEDGMENT}

I thanke Dr Mahmoud Kamali \& Mr Alireza Pakgohar for council me at regulationing question paper.

\section{REFERENCES}

[1] Persian News, mobile and social harms [Report], Tehran: author, May 2009,p1.

[2] Fazli, mobile phones cause mental disorders. Ideal communication ,Tehran: 2007, p1.

[3] Mobile information network in Iran, Pathology of mobile phone [Report] Tehran: author, 2009,p1. 
[4] Tabnak, the roots of Iranian youth addiction to mobile [Report], Tehran: autho, 2009,p1.

[5]Shirazi, P, brain targeted by waves of mobile phones. Jame Jam online, 2009,p1.

[6] Pyamavaran Noor, Bluetooth in warning situation, [ Report ] . Tehran: author, January 2008,(47) :p1.

[7] Abbasi, F, SMS is threat or opportunity, information ,Tehran: January 2008,p1.

[8],[14] Niksalehi, Bluetooth detrimental effects are more than its benefits [Report], Tehran: author, June 2009,p1.

[9] Ziba Web, most of addicts have low self-esteem. [Report], Tehran: author, March $2009, \mathrm{p} 1$.

[10].[16] Khoshfar, G, the effect of mass media on adolescent social ethics, Harif, 2008,p1.

[11] Farnam, H, the role of mobile phones in family conflicts from the perspective of a group of mobile phone subscribers in Yazd (project), Yazd, PNU, 2010,pp45-47.

[12]Tebyan, mobile phone, factor of divorce! [Report], Tehran: author, March 2009,p1.

[13] IRNA, usage of mobile by students is worrying, [Report]. Tehran: author, March 2009,p1.

[16] Iran Ikt News, the supply of Data card for professional use of GPRS [Report]. Tehran: author, March 2009,p1.

[17] Najafi Tavana, A., anomalies and juvenile delinquency, Tehran :Rahe Tarbiat, 2003,pp60-61.

[18],[19] Ardabil, MA, General Criminal Law, vol. II, Tehran:Mizan Press, 2000,pp27-29.

[20],[21] Specialized IT information base, to pursue mobile crimes in Dispute Resolution Council [Report], Tehran: author, January 2013,p1.

[22] Yargoli, M, the harms of an evil called mobile, Ziba web, December 2013,p1.

[23] Shirvani, Sh, used mobile phones, treasure secrets, Vista, 2013,p1.

[24] Network of Iran, you are disturbed by your mobile phone. [Report], Tehran: author, February 2012,p1.

[25],[30],[34],[35] IKTENA, mobile phones and Bluetooth crimes, [the report], Tehran: author, January 2013,p1.

[26] IRNA, Police warning on telephone fraud, [Report]. Tehran: author, January 2012,p1.

[27] Paknahad, NS, mobile phone and fraud, Iran track Forum, December 2011,p1.

[28] Tebyan, punishment awaits mobile hackers, [Report], Tehran: author, January 2013,p1.

[29],[31] Weblog Spy, spying tools in the hands of the members of parliament [report] Tehran: author, December 2013,p1.

[32] Weblog Spy, spying phone. [Report], Tehran: author, February 2012,p1. 
[33] Weblog Spy, Obama does not have the right to use iPhone, [Report, Tehran: author, December 2013,p1.

How to cite this article:

Hakimeh F. mobile phone social harms (mobile phone, communicative device or crime tool). J. Fundam. Appl. Sci., 2016, 8(2S), 1196-1212. 